Sarjiyah', Gatot Supangkat Samijo,

Eni Istiyanti ${ }^{3}$

1Prodi A groteknologi, Fakultas

Pertanian, U niversitas

M uhammadiyah Yogyakarta; Email:

sarjiyah@umy.ac.id

2Prodi A groteknologi, Fakultas

Pertanian, U niversitas

M uhammadiyah Yogyakarta; ${ }^{3}$ rodi

A gribisnis, Fakultas Pertanian,

U niversitas M uhammadiyah

Yogyakarta

Jalan B rawijaya, Tamantitrto,

K asihan, B antul, Yogyakarta 55163

\title{
Mewujudkan Desa Mandiri Pangan Melalui Pengelolaan Pekarangan
}

https:/ / doi.org/ 10.18196/ bdr.412

\begin{abstract}
ABSTRAK
Permasalahan yang dihadapi ranting 'Aisyiyah yakni pemanfaatan pekarangan umumnya untuk fasilitas umum, tanaman yang diusahakan di pekarangan kurang bernilai ekonomi, pengetahuan, wawasan dan ketrampilan anggota 'Aisyiyah dalam pemanfaatan pekarangan dan teknik budidaya tanaman masih terbatas.. Tujuan pengabdian pada masyarakat ini, yaitu meningkatkan pengetahuan, wawasan dan ketrampilan kelompok Aisyiyah Wedomartani dan Argomulyo dalam pemanfaatan pekarangan. Metode yang digunakan dalam pelaksanaan kegiatan, meliputi penyuluhan, pelatihan dan praktik serta fasilitasi material penunjang. Teknologi budidaya yang diterapkan dalam pemanfaatan pekarangan, yaitu hidroponik, vertikultur, whick pot dan penanaman dalam pot.Hasil pengabdian pada masyarakat menunjukkan bahwa penerapan teknologi budidaya tanaman secara hidroponik dan penanaman dalam pot dapat diterima dan dilakukan dengan baik oleh kelompok Aisyiyah di Wedomartani, dan Argomulyo. Pemanfaatan pekarangan dengan tanaman sayuran, buah dan obat dilakukan dengan sungguh-sungguh oleh masyarakat, khususnya kelompok Aisyiyah di Wedomartani dan Argomulyo sebagaimana hasil monitoring dan evaluasi selama kegiatan dan paska kegiatan.

Kata kunci : Kemandirian pangan, Pemanfaatan Pekarangan, 'Aisyiyah, Hidroponik, Tabulampot
\end{abstract}

\section{PENDAHULUAN}

U ndang-U ndang Republik Indonesia Nomor 7 Tahun 1996 tentang Pangan dijelaskan bahwa Pemerintah bersama masyarakat bertanggung jawab untuk mewujudkan ketahanan pangan, dan menurut Peraturan Pemerintah Republik Indonesia N omor 68 Tahun 2002 tentang Ketahanan Pangan bahwa masyarakat memiliki kesempatan untuk berperan seluas-luasnya dalam mewujudkan ketahanan pangan melalui pelaksanaan produksi, perdagangan dan distribusi, penyelenggaraan cadangan pangan masyarakat, serta pencegahan dan penanggulangan masalah pangan.

Aisyiyah sebagai gerakan perempuan Muhammadiyah telah berkiprah dan memberikan kontribusi dalam usaha-usaha memajukan kehidupan umat, bangsa, dan 
dunia internasional. Aisyiyah mengemban misi dakwah dan tajdid, memiliki visi gerakan yang harus diwujudkan dalam menghadapi dinamika kehidupan zaman yang bersifat kekinian menuju tercapainya tujuan masyarakat Islam yang sebenar-benarnya yang membawa rahmat bagi semesta alam. A isyiyah dihadirkan untuk mewujudkan kehidupan perempuan berkemajuan dalam seluruh aspek kehidupan. U ntuk itu, peran Aisyiyah dalam membantu penyediaan pangan secara mandiri sangat diperlukan.

Salah satu upaya dalam mewujudkan kemandirian pangan yakni pemanfaatan lahan pekarangan di pedesaan maupun perkotaan secara optimal dengan mengusahakan tanaman pertanian baik tanaman sayuran, buah, obat maupun pangan. Lahan pekarangan yang relatif luas dapat diusahakan dengan perikanan dan ternak. O ptimalisasi pemanfaatan lahan pekarangan ditujukan untuk memenuhi kebutuhan pangan keluarga secara mandiri.

Program nasional gerakan menanam tanaman di pekarangan rumah dalam rangka mewujudkan ketahanan pangan, kemandirian pangan dan kedaulatan pangan sudah dicanangkan sejak 2015 dan setiap warga rumah tangga wajib berpartisipasi dalam kegiatan tersebut. Aisyiyah sebagai organisasi gerakan mempunyai peran strategis dalam menggerakkan warganya untuk dapat melakukan program tersebut demi mewujudkan ketahanan pangan, kamandirian dan kedaulatan pangan.

Beberapa permasalahan yang dihadapi oleh kedua kelompok ranting Aisyiah yakni pemanfaatan pekarangan umumnya untuk fasilitasumum, tanaman yang diusahakan di pekarangan kurang bernilai ekonomi, pengetahuan, wawasan dan ketrampilan anggota 'Aisyiyah dalam pemanfaatan pekarangan dan teknik budidaya tanaman masih terbatas. Beberapa permasalahan yang dihadapi oleh kedua kelompok ranting Aisyiah membutuhkan penanganan agar lahan pekarangannya lebih produktif, solusinya peningkatan wawasan dan ketrampilan anggota 'A isyiyah dalam pengelolaan pekarangan melalui penerapan teknologi budidaya tanaman yang produktif, antara lain vertikultur, hidroponik, whick pot serta bertanam sayuran dan buah dalam pot.

\section{METODE PELAKSANAAN}

M etode yang digunakan, meliputi penyuluhan, pelatihan, praktik aplikasi teknologi, serta pendampingan dan monitoring evaluasi. Kegiatan penyuluhan dilakukan dengan mengumpulkan anggota Ranting 'Aisyiyah untuk mengikuti penyuluhan tentang pengelolaan pekarangan. Beberapa materi yang diberikan antara lain arti penting ketahanan dan kemandirian pangan, pengelolaan pekarangan, teknologi dalam pengelolaan pekarangan. 
U ntuk memfasilitasi pelatihan dan praktek pengelolaan pekarangan, dilakukan transfer teknologi dengan pengadaan peralatan vertikultur, hidroponik, whick pot dan tabulampot, serta fasilitas lain yang mendukung kegiatan ini.

Pelatihan dan praktik dilakukan dengan simulasi penerapan teknologi vertikultur, hidroponik, whick pot serta penanaman sayuran dan buah dalam pot menggunakan peralatan dan bahan yang sudah disiapkan oleh Tim Pelaksana program. Pelatihan dilakukan oleh Tim Pelaksana program, dengan diikuti oleh anggota Ranting 'Aisyiyah. Setelah penyuluhan, pelatihan dan praktik, seluruh anggota 'Aisyiyah melakukan praktik budidaya dengan teknologi vertikultur, hidroponik, whick pot serta penanaman buah dalam pot dengan dibimbing oleh Tim Pelaksana program..

Kegiatan pendampingan dan monitoring
Gambar 1. Koordinasi di Wedomartani dan di Argomulyo

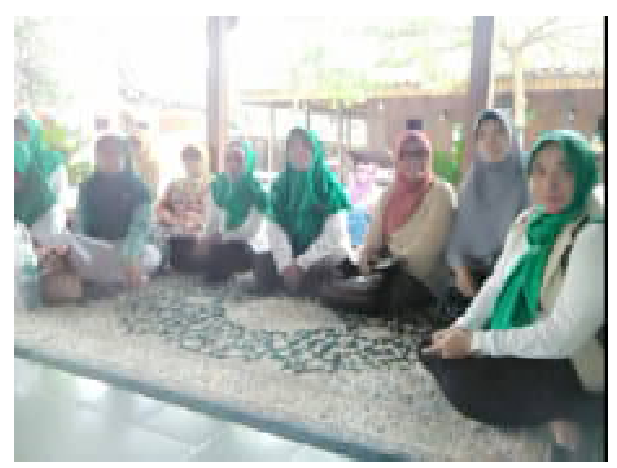

Wedomartani, Oktober 2016

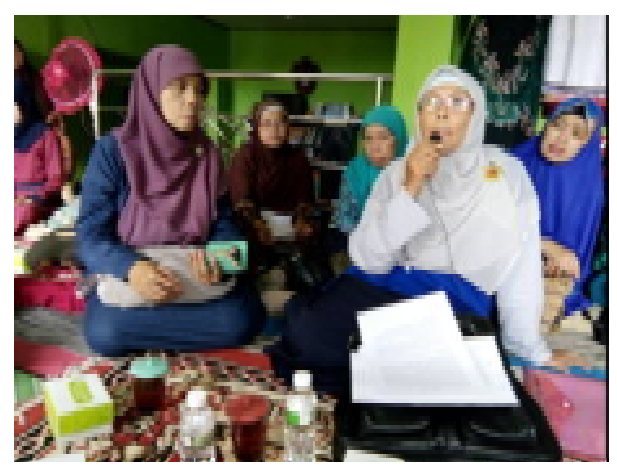

Argomulyo, Maret 2017

evaluasi dilakukan secara periodik untuk membina dan mendampingi mitra sampai berhasil melakukan praktek penerapan teknologi budidaya tanaman, serta anggota Ranting'A isyiyah dapat berkonsultasi tentang pelaksanaan program sampai mencapai hasil yang optimal.

\section{HASIL DAN PEMBAHASAN}

Koordinasi dan Observasi

Langkah awal kegiatan IbM adalah koordinasi, yang dilakukan untuk menyamakan persepsi antar pihak yang terkait serta menyusun langkah strategis pelaksanaan program. Kegiatan ini dilakukan dengan mengadakan kunjungan ranting 'A isyiyah Wedomartani dan Argomulyo. Pada kegiatan ini disampaikan tentang gambaran umum kegiatan, didiskusikan pengaturan jadual kegiatan, dan observasi kondisi lingkungan Desa Wedomartani dan Argomulyo (Gambar 1).

\section{Sosialisasi}

Kegiatan sosialisasi dan penyuluhan di ranting 'A isyiyah Wedomartani dibuka oleh 
Ketua MEK PPA dan MEK PWA, dan diikuti oleh perwakilan dari MEK PDA se DIY masing-masing 2 orang dan seluruh anggota Ranting 'A isyiyah Wedomartani, dengan nara sumber Tim Pelaksana yang sudah mempunyai pengalaman dalam pengelolaan pekarangan perkotaan dengan teknologi vertikultur dan hidroponik (Gambar 2). Kegiatan sosialisasi, penyuluhan dan diskusi di ranting 'A isyiyah A rgomulyo, dibuka oleh Ketua Div Ketahanan Pangan MEK PPA dan MEK PWA, dan diikuti oleh perwakilan dari MEK PDA se DIY masing-masing 2 orang dan seluruh anggota Ranting 'Aisyiyah Argomulyo (G ambar 3).
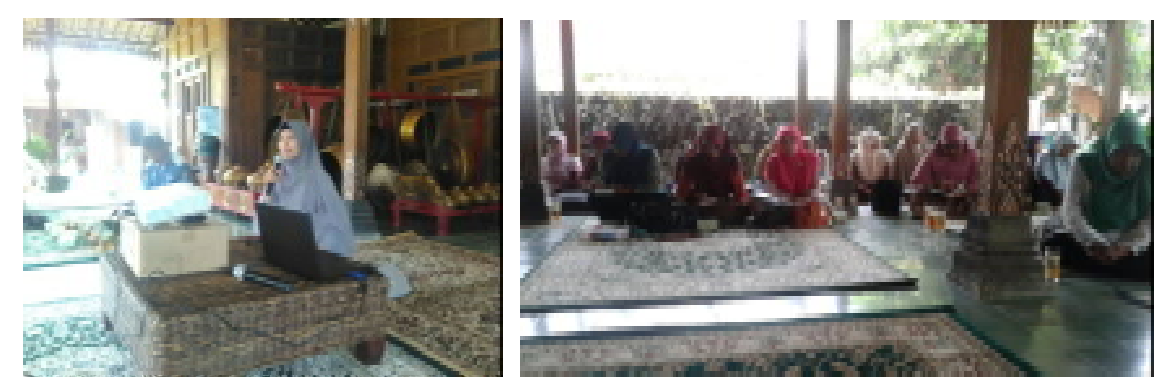

Wedomartani, 23 Oktober 2016

Gambar 2. Sosialisasi dan penyuluhan di Ranting 'Aisyiyah Wedomartani
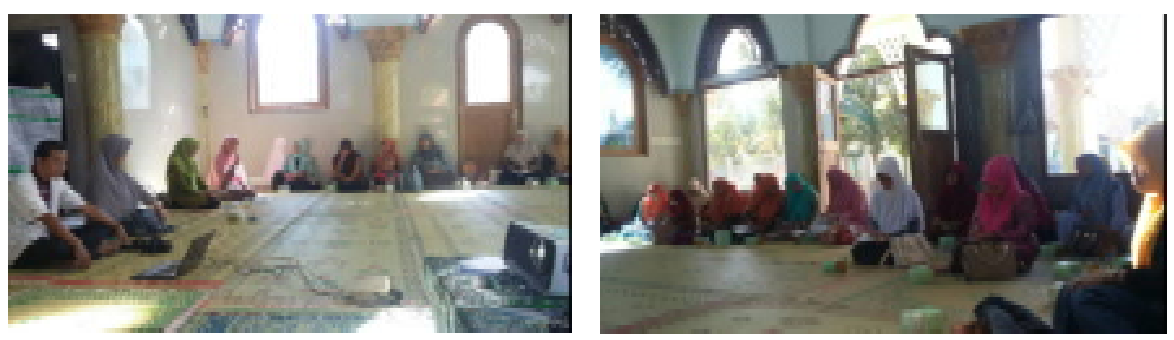

Argomulyo,16 J uli 2016

Gambar 3. Sosialisasi dan penyuluhan di Ranting 'Aisyiyah Argomulyo

Materi yang disampaikan dalam penyuluhan adalah program ketahan pangan dan kemandirian pangan, pengelolaan pekarangan pedesaan dan perkotaan, teknologi budidaya tanaman secara vertikultur, hidroponik sertatanaman sayuran dan buah dalam pot. Dalam penyuluhan banyak tanggapan dari peserta terutama tentang bahan untuk vertikultur, hidroponik, jenis tanaman yang dapat diusahakan di pekaranagan, pemeliharaan dan proteksi tanaman.

\section{Pelatihan dan Praktik Budidaya Tanaman di Pekarangan}

Kegiatan praktik budidaya tanaman pekarangan dilakukan di dua tempat dengan kondisi wilayah yang berbeda yaitu pekarangan yang relatif sempit (di Ranting 'A isyiyah Wedomartani) dan pekarangan yang relatif luas ( di Ranting 'A isyiyah A rgomulyo). 


\section{Praktek Budidaya Tanaman Pekarangan di Ranting 'Aisyiyah Wedomartani}

Kegiatan praktek budidaya tanaman pekarangan dilakukan setelah penyuluhan. dengan diawali penjelasan macam instalasi alat vertikultur dan hidroponik, penyiapan alat dan bahan, penyiapan media tanam, dan penanaman. Penjelasan teknis pertanaman secara vertikultur dan hidroponik dilakukan oleh Tim pelaksana dan diikuti oleh perwakilan dari seluruh ranting 'Aisyiyah se Kab. Sleman (Gambar 4). Kegiatan ini bertujuan agar setiap anggota 'A isyiyah dapat meningkatkan potensi lahan pekarangan untuk ketersediaan pangan keluarga dengan penanaman sayuran dengan teknik vertikultur dan hidroponik.

Setelah pengenalan macam instalasi vertikultur dan hidroponik selesai, ibu-ibu anggota 'Aisyiyah dibimbinguntuk melakukan penyiapan media tanam yang terbuat dari campuran tanah, sekam padi dan pupuk kandang pada teknik vertikultur, sedangkan sistem hidroponik menggunakan media tanam air yang dicampur dengan nutrisi (pupuk cair) tanaman dengan perbandingan $1 \mathrm{ml} / \mathrm{l}$ air.

Selanjutnya media tanam vertikultur dimasukkan dalam wadah secara penuh dan selanjutnya disiram air sampai cukup basah, apabila media tanam memadat, ditambahkan media tanam lagi sampai penuh. Sedangkan media tanam hidroponik (air + pupuk cair) dimasukkan dalam bak plastik (ember) yang akan dialirkan keinstalasi hidroponik menggunakan pompa elektrik, sambil menunggu bahan tanam (bibit) siap untuk ditanam.

Bersamaan dengan penyiapan media tanam juga dipersiapkan bahan tanam berupa bibit tanaman sayuran. Bibit dipilih yang pertumbuhannya baik, seragam dan tidak
Gambar 4. Pelatihan dan Praktik

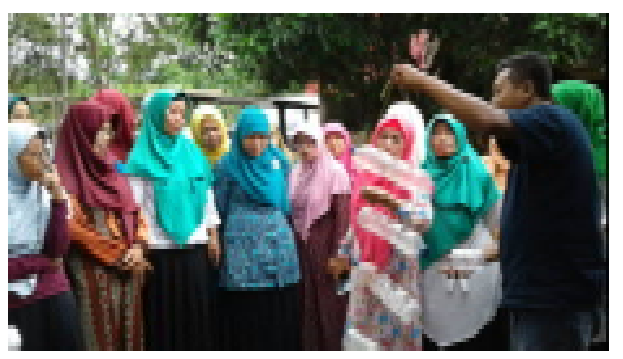

Sistem tanam vertikultur

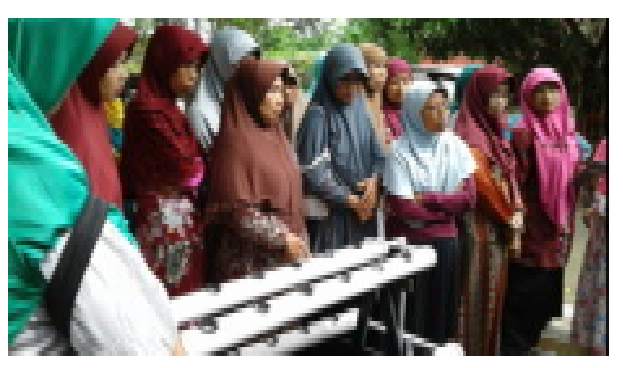

hidroponik
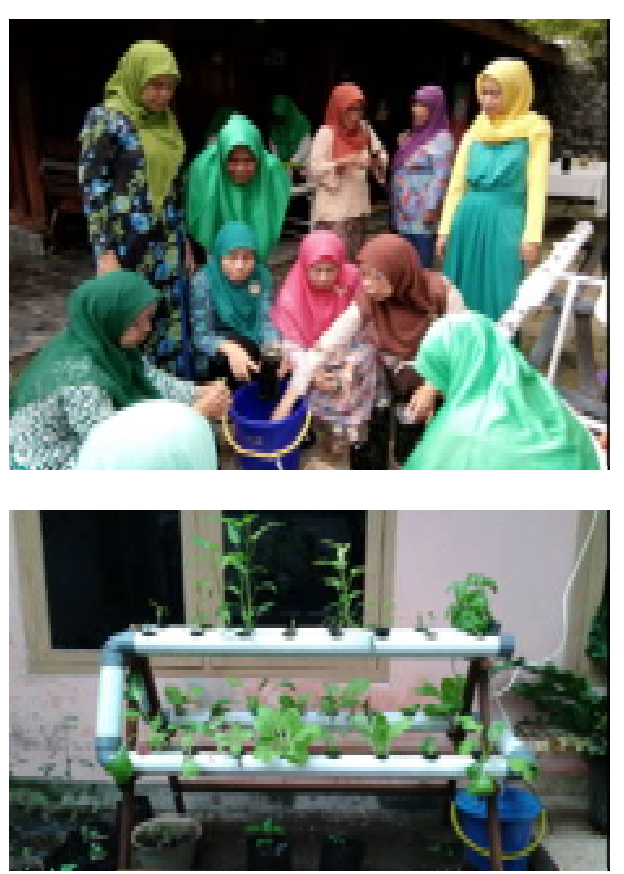

Gambar 5. Praktek penyiapan media dan penanaman sistem hidroponik 
terkena serangan organisme pengganggu tanaman. Bibit yang ditanam dalam wadah vertikultur menggunakan pipa pralon atau botol dan sistem hidroponik adalah bibit selada, seledri, pakcoy, sawi putih, dan caisim.

Setelah media tanam dan bibit siap, selanjutnya dilakukan penanaman bibit sayuran pada instalasi vertikultur dan hidroponik. Setelah penanaman dilakukan penyiraman dengan air secukupnya pada system vertikultur, sedangkan penanaman dengan sistem hidroponik diperlukan pot kecil dan spon untuk menanam dan menegakkan tanaman. Setelah tanaman ditanam pada spon dalam pot kecil, maka air dalam bak plastik/ ember segera dialirkan ke instalasi hidroponik dengan menyalakan pompa elektrik ( $G$ ambar 5.).

\section{Praktik Budidaya Tanaman Pekarangan di Ranting 'Aisyiyah Argomulyo}

Kegiatan budidaya tanaman di pekarangan dilakukan setelah penyuluhan. dengan diawali penjelasan macam tanaman yang dapat dibudidayakan di pekarangan,, penyiapan media tanam, dan penanaman. Penyuluhan, pelatihan dan praktik budidaya tanaman di pekarangan dilakukan oleh Tim pelaksana dan diikuti oleh perwakilan dari seluruh ranting 'Aisyiyah se Kab. Bantul dan 'Aisyiyah W ilayah se DIY .
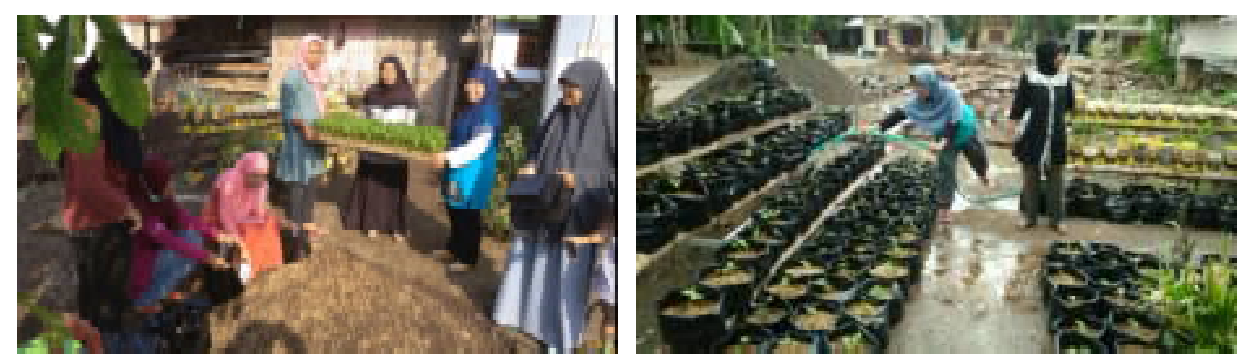

Gambar 6. Penyiapan medium tanam dan penanaman bibit sayuran di Argomulyo

Pelatihan dan praktek diawali dengan menyiapkan media tanam yang terdiri dari campuran tanah, jerami padi dan pupuk kandang dengan perbandingan $3: 1: 1$ yang akan digunakan untuk penanaman berbagai tanaman sayuran dalam pot/ polibag/ plastik bekas kemasan minyak, sambil menunggu bibit siap tanam (umur bibit kurang lebih 3 minggu). Penanaman dilakukan 1 minggu setelah penyiapan media tanam. M edia tanam yang sudah disiapkan dalam wadah/ polibag diberi air sampai lembab, kemudian dibuat lubang tanam untuk menannam bibit yang sudah disiapkan (Gambar 6). Tidak semua jenistanaman sayuran ditanam dengan bibit, tetapi bisa ditanam langsung dengan biji/ benih sepeerti kangkung, bayam, kacang panjang, koro, kecipir (kacangkacangan). 
Fasilitasi

A gar supaya anggota 'A isyiyah dapat mempraktekkan dan mengembangkan tanaman sayuran dengan sistem hidroponik maka diberikan bantuan instalasi hidroponik sebanyak 20 buah dan bibit tanaman sayuran yang ditempatkan pada titik-titik yang tersebar utuk menjadi percontohan (G ambar 7.). Sedangkan, untuk pengembangan tanaman sayuran dan buah dalam pot di ranting "Aisyiyah Argomulyo diberikan bantuan bibit cabai sebanyak 200 bibit dan 50 bibit jambu Kristal.
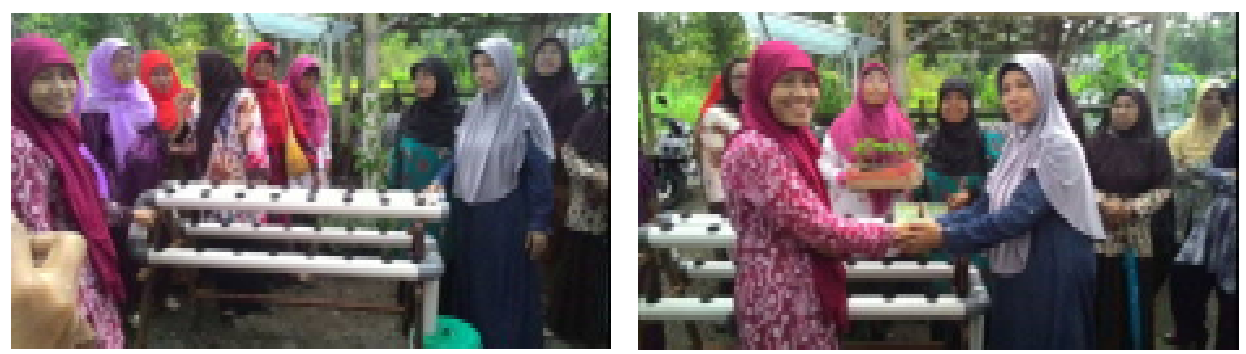

Gambar 7. Penyerahan bantuan 20 instalasi hidroponik di Wedomartani

\section{Pendampingan}

Kegiatan pendampingan dan konsultasi dilakukan secara periodik untuk membina dan mendampingi anggota 'A isyiyah sampai berhasil melakukan budidaya tanaman secara vertikultur dan hidroponik. Kegiatan ini dilakukan dengan melakukan kunjungan untuk monitoring dan evaluasi, serta memberikan masukan kepada anggota 'Aisyiyah (Gambar 8).
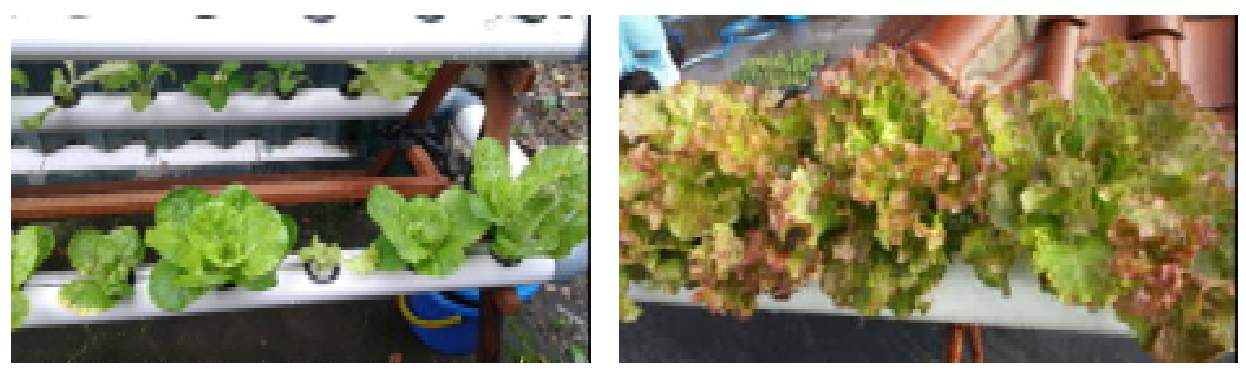

Gambar 8. Pertanaman dari bantuan instalasi hidroponik saat monev di Wedomartani

Kegiatan pendampingan juga dilakukan untuk memberikan arahan dalam pemeliharaan antara lain dengan penyiraman, pemupukan dan pengendalian hama dan penyakit. Penyiraman merupakan aspek yang sangat penting karena media tanam di dalam wadah terbatas volumenya sehingga agar tanaman dapat bertahan hidup diperlukan kecukupan air. U ntuk memenuhi kebutuhan air, maka media tanam disiram dengan frekuensi tergantung pada kondisi tanah. Pemeliharaan yang lain adalah pemupukan, dilakukan menggunakan pupuk nitrogen \ urea dengan cara disemprotkan atau 
dikocorkan pada mediatanam. Pupuk yang digunakan hanya nitrogen saja karena selain pada media tanam sudah diberikan pupuk kandang, juga karena tanaman yang diusahakan hasilnya berupa daun sehingga perlu kecukupan nitrogen. Proteksi tanaman dilakukan den gan cara mencabut gulma atau rumput yang tumbuh pada media tanam, sedangkan hama atau penyakit relatif sedikit, secara manual diambil dan dihilangkan/ dimatikan. Pemeliharaan tanaman den gan sistem hidroponik relatif lebih mudah, tidak perlu menyiram dan memupuk, hanya perlu menambah larutan nutrisi dalam bak plastik (ember) bila debit berkurang. Hama dan penyakit relatif sedikit, pengendalian cukup dilakukan secara manual dengan menghilangkan dengan tangan.

$\mathrm{H}$ asil monitoring dan evaluasi yang dilakukan oleh tim pelaksana, bahwa anggota'Aisyiyah di Wedomartani lebih tertarik budidaya tanaman secara hidroponik dikarenakan budidaya dengan sistem ini tidak menggunakan tanah sebagai media tanam sehingga terkesan lebih bersih tempatnya dan tidak perlu menyiram dan memupuk. Sebagian besar sudah berhasil baik sampai dipanen, sebagian pertumbuhan masi helum maksimal dan ada juga yang masih gagal. Setelah mendapatkan arahan, yan g gagal sudah berani mencoba lagi dan sudah berhasil. Kendala yang dirasakan untuk keberlanjutan usaha tanaman hidroponik ini adalah ketersediaan bibit dan pupuk/nutrisi. Karena tanaman sayuran yang ditanam adalah tanaman semusim, maka setelah dipanen harus diganti tanaman baru. Oleh karena itu untuk kontinyuitas produksi/ penanaman diperlukan bibit tanaman sayuran yang diusahakan/dikelola secara bersama-sama (kelompok).

Pendampingan dan monitoring di ranting "Aisyiyah A rgomulyo dilakukan 1 bulan setelah dilakukan penanaman, dengan berkunjungdi beberapa anggota 'A isyiyah yang melakukan praktek pengelolaan pekarangan (Gambar 9).
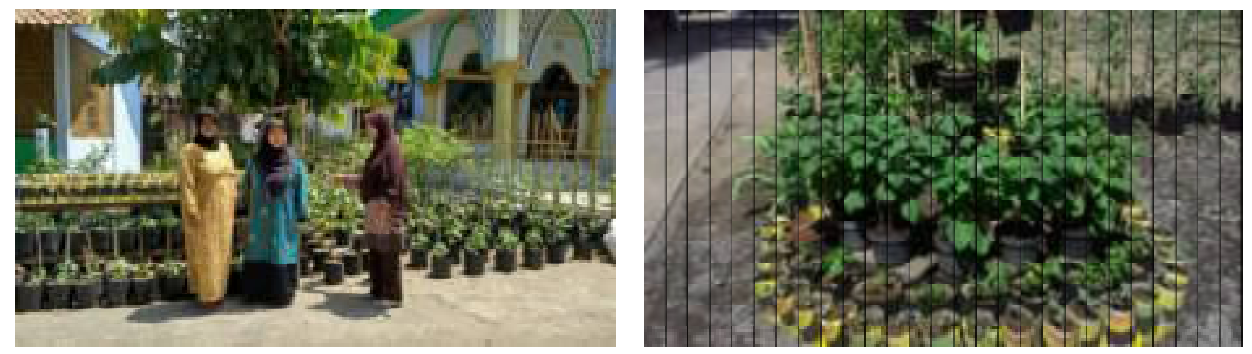

Gambar 9. Monev di ranting 'Aisyiyah Argomulyo

Dari hasil monitoring, ibu-ibu anggota 'Aisyiyah R anting Argomulyo sudah berhasil mempraktekkan pengelolaan pekarangan dengan menanam tanaman sayuran, buah dan 
obat di pekarangannya, bahkan ada diantaranya menjadikan usaha bertanam di pekarangan menjadi bisnis dengan menjual produk tanaman sayuran, buah dan obat, bahkan dipasarkan dalam bentuk tanaman dalam pot/polibag karena lokasinya berdekatan dengan lokasi wisata M useum Soeharto di dusun Kemusuk, Argomulyo, Bantul DIY.

\section{Dampak}

Secara keseluruhan, kegiatan pengabdian penerapan ipteks bagi masyarakat yang dilakukan di Ranting 'Aisyiyah Wedomartani dan Argomulyo sudah terlaksana dan berjalan dengan baik. Seluruh anggota ;A isyiyah memberikan tanggapan yang positif dan dengan senang hati mengikuti kegiatan secara penuh dan dapat mempraktekkan pengelolaan pekarangannya dengan menanam tanaman sayuran, buah dan obat baik dengan sistem hidroponik maupun menggunakan pot/ polibag. Produk tanaman yang diusahakan di pekarangan dapat memenuhi kebutuhan sebagian bahan pangan keluarga, bahkan ada diantara mereka yang menjadikan kegiatan bisnis dengan menjual/ memasarkan produk tanaman maupun tanaman dalam pot/ polibag. M eskipun demikian, untuk memberikan jaminan kebelanjutan, Tim Pelaksana tetap akan menjalin kerjasama dengan pimpinan ranting 'Aisyiyah Wedomartani dan Argomulyo untuk melakukan pendampingan dan pembinaan, terkait dengan tema pengabdian,

\section{SIM PULAN}

1. Tahapan kegiatan yang dilakukan sebagai bentuk solusi atas permasalahan yang dihadapi masyarakat, yaitu sosialisasi dan penyuluhan, pelatihan dan praktik penanaman tanaman sayuran, buah dan obat secara vertikultur, hidroponik dan menggunakan pot, pendampingan serta monitoring dan evaluasi.

2. Seluruh anggota "Aisyiyah memberikan tanggapan yang sangat baik dengan berpartisipasi dan mengikuti kegiatan secara penuh dan dapat melakukan praktik penanaman tanaman sayur, buah dan obat di pekarangannya.

3. Keberhasilan kegiatan pemberdayaan di Ranting 'Aisyiyah Wedomartani dalam pengelolaan pekarangan diujudkan dengan keberlanjutan penanaman sayuran secara hidroponik, sedangkan di Ranting 'Aisyiyah Argomulyo dengan keberlanjutan budidaya tanaman sayuran, buah dan obat dalam pot

4. Produk dari kegiatan pemberdayaan dapat memenuhi kebutuhan bahan pangan keluarga, bahkan bisa dikembangkan menjadi kegiatan bisnis sehingga dapat 
menambah pendapatan keluarga.

5. Jaminan kebelanjutan pemberdayaan yang telah dilakukan diujudkan dengan pengikatan kerjasama dengan Pimpinan Ranting 'Aisyiyah dalam pendampingan dan pembinaan pengembangan kegiatan.

\section{UCAPAN TERIMA KASIH}

Atas selesainya kegiatan Ipteks Bagi Masyarakat ini, Tim Pelaksana memberikan apresiasi dan penghargaan setinggi-tingginya kepada LP3M U MY yangtelah memfasilitasi kegiatan ini, Staf dan Laboran Laboratorium Produksi Tanaman U MY, mahasiswa pembantu pelaksana dan semua pihak yang telah berpartisipasi dan ikut membantu guna kelancaran kegiatan ini.

\section{DAFTAR PUSTAKA}

Anonim. 2013. Budidaya Tanaman Sayuran secara Vertikultur Sederhana. http:// pustakapertanianub. staff.ub.ac.id/2013/01/19/ budidaya-tanaman-sayuran-secara-vertikultursederhana/

Agus Andoko. 2014. Budidaya Sayuran Secara vertikultur Organik. Penebar Swadaya
Delima Hasri Ashahari. 2013. Membangun Kemandirian pangan dalam rangka meningkatkan ketahanan Nasional. Litbang Pertanian.go.id.

Hervin Sasono dan Novian. 2014. Mudah Membuahkan 38 Buah Tambulapot Paling Populer. Gramedia Group.

Untung Prasetyo. 2016. Bertanam Sayuran Secara Hidroponik Pekarangan. Agromedia Pustaka. 